\title{
Research on the Development Model of Black Copper Walking on Silver in Vitality Inheritance and Industrialization
}

\author{
Chen Wang1, Xueling Ren", a \\ ${ }^{1}$ School of Fine Arts, Qingdao University, Qingdao, Shandong Province, 266071, China \\ a786548362@qq.com
}

\begin{abstract}
Black Copper Walking on Silver ", the unique copper production process in Yunnan, as an important part of the excellent traditional Chinese culture, its inheritance has far-reaching significance for us to establish cultural confidence and rebuild cultural identity. However, the current development of black copper and silver walking technology is difficult, and the traditional sense of protection has been unable to solve the root problem. Nowadays, the protection of black copper and silver walking skills should break the traditional static single protection mode, combine the traditional inheritance with modern protection, and grasp the intangible cultural heritage elements from the perspective of productive protection. On the basis of objectively analyzing the characteristics and development status, the article effectively connects the living inheritance with industrialization, and explores the new development mode of folk custom industrialization under the live inheritance mode, so as to promote the live inheritance of black copper walking on silver and the common development of folk economy industry.
\end{abstract}

Keywords: Black Copper Walking on Silver, Iive Inheritance, Industrialization, Traditional Handicraft.

\section{Introduction}

The inheritance of traditional skills verifies the development process of the cultural essence of the Chinese nation. The black copper and silver walking skills have profound cultural deposits and obvious technological characteristics, and the combination with other characteristic folk industries in Yunnan can further boost the development of regional economy. [1] "The Implementation Opinions on Kunming City Implementation of the 'Yunnan Traditional Process Revitalization Action Plan' "clearly pointed out that by 2020, the city should form a number of traditional craft theme and product variety, cultivate a number of well-known brands with high design and production level, and cultivate a group of talents with strong inheritance and innovation ability. (Official website of Kunming Municipal Finance Bureau, 2019-5-7,http://czj.km.gov.cn/c/2019-05-07/3002544.shtml) Under the development opportunity, study the new direction of the development of copper silver products, and assist the inheritance and development of copper silver skills from the industrialization perspective through hierarchical processing method. Through the progressive discussion, and on the basis of analyzing the art characteristics and living inheritance status of black copper and silver walking skills, explore the endogenous relationship between its living inheritance and industrialization development. Finally, by combining with Yunnan local characteristics, build the system model of silver industrialization development, explore the new mode of silver inheritance and industrialization development from the perspective of creation and activation.

\section{Current Status of Yunnan Copper}

"Black copper walking on silver" is the traditional copper crafts manufacturing skills produced in Shiping County, Yunnan Province. It is made with alloy copper, chisel various decorative patterns on the copper tire, and then fill the melted silver (or gold) into the chisel pattern, cool and polishing, and then rub it with your hands to become black and shiny "black copper walking on silver (or gold)".Black copper and silver line color has excellent decorative effect, silver surface decoration pattern is simple and elegant, theme more absorb Confucian, Buddhist culture auspicious patterns, more flowers and birds, insects, words, freehand landscape painting and geometric patterns as the theme, reflect the spirit of Yunnan people, reflects the profound historical precipitation, displayed in Yunnan hall "Grand View Building" painting screen is the representative work of black bronze walk silver. [2].

As the most representative copper ware making process in Yunnan, it interprets the essence of copper ware making in Yunnan for hundreds of years, but its development road is rugged and bumpy, wandering on the verge of loss. In June 2011, the production skills of "Black Copper Walking on Silver " were officially listed in the third batch of national intangible cultural heritage list. [3] However, the inclusion of "intangible cultural heritage" can not clear all "obstacles" for the development of black copper and silver. The birth and inheritance of any traditional skill are closely related to its specific ecological environment, created because of the environment and died because of the environment. The black copper and silver walking technology is separated from the original cultural and ecological environment and isolated, which is bound to lose its vitality. Nowadays, problems such as no successor, valuable scarcity of raw materials and lack of innovation have seriously restricted the inheritance and development of black copper and silver. Since the founding of the People's Republic of China, the Yunnan Provincial government is actively rescuing protection. For example, in the 1970 s, Kunming Spot Copper Factory has carried out rescue research on Ukrainian copper walking technology, and tried to make major breakthroughs in combining with spotted copper, among which the representative work "Peacock Meditation" was permanently collected by the original 
Department of arts and crafts treasures as the Ministry of Light Industry. [2] After that, many research institutions or individuals such as Guiyuan Platinum Co., Ltd. and other research institutions have tested and copied the composition of black copper and achieved certain results, alleviating the crisis of the imminent extinction of Black Copper Walking on Silver.

Through the existing materials and exhibition halls of the existing non-genetic inheritance project and the physical products displayed, it is mainly static protection. Its purpose is to preserve the black copper silver walking technology as a cultural relic for a long time. However, the basic characteristics of the living rheology of the intangible cultural heritage determine that our protection today should not be only static, frozen protection, but more for development protection. Without protection, it is difficult to develop; without development, protection loses its significance. [4] If in order to protect and inherit the Black Copper Walking on Silver process, the correct way is to retrace the historical process of its generation and development, investigate its natural condition factors, explore the social organization factors of its inheritance, and understand the thriving economic demand factors and the background factors of its decline. [5] Only can we deeply explore the modern development path of Black Copper Walking on Silver and produce higher social value and economic benefits. On this basis, sustainable vision is necessary to inherit copper silver, the innovation of the protection, capital investment and infrastructure construction, and civic participation.

\section{The Interconnection between the Living Inheritance and Industrialization of Yunnan Black Copper and Silver Walking Technology}

The development of copper silver industry is a serialized and brand management mode and organizational form based on Yunnan geography, history, resources, production and life, inheritance, dissemination, promotion and development of traditional culture, taking the realization of economic benefits as the goal, and relying on professional service and quality management. [1] Wu Copper and silver inheritance and the development of folk industry are not only an important way to develop folk industry, but also an inevitable requirement for black copper and silver to integrate into modern life to achieve sustainable development. Black Copper Walking on Silver, which contains rich cultural skills information, has great development potential, its internal interaction with the folk industry, and the relationship between the two is dialectical and unified.

\subsection{Providing Original Materials and Cultural Support for the Folk Culture Industry}

The excellent traditional Chinese culture created and continued by the Chinese nation in thousands of years of history is the root and soul of the Chinese nation. It is a strong core resource and basic force in China's cultural industry, and the starting point and destination of the infinite extension of innovative forms. [6] The silver walking technology provides a large number of simple and real cultural resources for the development of folk industry. The characteristics of the silver technology is in the silver line out of the silver piece, its effect is similar to the Chinese painting, a wide variety of patterns: or concrete patterns, such as plum orchid bamboo and chrysanthemum, bats, cranes and other auspicious patterns; or freehand landscape painting; also have geometric patterns, such as Swastika decoration pattern, Buddha heirloom, etc. The silver pattern perfectly conveys the traditional Chinese aesthetic thought. It is different from all the realistic patterns on western handicrafts at a glance, which is more to express a profound meaning, hiding the endless cultural meaning in the square pattern pattern, implicit, introverted and implicit and profound meaning. The bronze walking silver implements take copper as the tire, silver (or gold) as decoration, and integrate two different materials into one object, which is the embodiment of the "harmony" of the traditional Chinese philosophy. This concept runs through the traditional views of universe, world, country, family and morality. Its black and white colors are the same as Chinese gossip, and Yin and Yang are both opposite and unified.

\subsection{Promoting the Internationalization of Regional Characteristic Economy}

Regional characteristic culture is the basic element of folk culture, and the development of folk culture industry under the guidance of regional culture can further boost the economic development of the region. Under the background of the state advocating improving cultural soft power and promoting the "going global" of Chinese culture, the "Black Copper Walking on Silver " skill, as an indispensable part of excellent traditional culture, undertakes the responsibility of excellent cultural dissemination and is an important carrier of Chinese culture for "going global". [7] However, the "going global" of "Black Copper Walking on Silver " skills must integrate, processed and refined its cultural products and services, and through market-oriented subjects and channels to achieve the long-term export of culture. From this point of view, the "Black Copper Walking on Silver " skill is not only a precious cultural resource, but also an important economic resource.

In the process of internationalization, it is integrated into the design and development of copper walking products on the basis of comprehensive cultural needs and aesthetic characteristics of overseas markets. Driven by the representative inheritor of the National Intangible Cultural Heritage Project and the Black Copper Walking on Silver Training Museum, they actively conducted cultural exchanges with other countries in the world and promoted the skills of "copper silver" overseas. National non-hereditary bearing Jin Yongcai combined with foreign innovative elements production of tea, tripod, incense plug, furnace, with its unique technology and exquisite production, enjoys a high reputation at home and abroad, its works in Japan, Geneva, the United States, Germany and other countries exhibition exchange, and by the German Chinese cultural center and other institutions collection.

\section{Research on the Industrialization Development Mode of Black Copper Walking on Silver Folk Products}

Industrialization is the best way to help and promote the inheritance of black copper and silver. It is also the core of promoting the transformation of cultural capital into innovative productive forces and into new economic growth points represented by the cultural industry. Only through 
industrialization can black copper silver folk products be connected with the market, follow market demand and make the "still life of history" alive, so as to fully explore their "potential wealth". For more people, can the own value of black copper silver be infinitely magnified and be inherited indefinitely. [6] However, the pursuit of economic benefit maximization is the internal law and logic of market economy. Folk culture industry is different from general industries, which has the dual ideological and industrial attributes. The development of folk culture industry must fully consider its particularity, its ideological attributes and the value of art, aesthetic, culture and other aspects. Therefore, it is particularly important to discuss the industrialization under the living background of Black Copper Walking on Silver inheritance. Industrialization operation of Black Copper Walking on Silver is not to make it a complete commercialization of fast consumer product type. The purpose of industrial operation is consistent with the goal of live inheritance and protection of Black Copper Walking on Silver. As long as the orderly and benign operation, we can protect and inherit the black, copper and silver walking skills.

\subsection{Accurate Grasp of the Traditional Elements}

The core competitiveness of intangible cultural heritage lies in the essence of excellent traditional culture. In the process of the industrialization of black copper and silver, we should not only dig into the deep traditional culture and keep pace with the times and meet the needs of the development of the times. Under this premise, must establish the investigation, establishment of silver folk creative industry system, classification, evaluation, supervision system, copper, organize relevant intangible experts for field investigation of the Yunnan Black Copper Walking on Silver skills, analyze its process characteristics and development advantages of industrialization, on the basis of the better development of copper silver, formulate specific and feasible inheritance standards. On the basis of scientific evaluation, increase the investment of human, financial and material resources, and use the power of the market for the scientific development and protection. In the process of industrialization development, immersion experience methods can be used for marketing and publicity, such as: chisel experience, device beating experience, etc. You can also combine the decorative pattern of Black Copper Walking on Silver and the unique device type into the local characteristic tourism supplies, clothing design, souvenir design, for industrialization development. It can not only dig deep into the cultural connotation, but also provide more jobs to drive employment and drive the economic development of Yunnan. Only by grasping the essence of black copper silver tradition into industrialization development can we grasp the main line of its inheritance and protect black copper silver.

\subsection{Enhance the Brand Awareness}

"The Development Plan of Cultural Industry during the 13th Five-Year Plan period of the Ministry of Culture" clearly points out the importance of "strengthening the construction of cultural brand". [6] Looking at the overall situation of China 's cultural industry, the intangible cultural heritage is "intangible cultural heritage". In China' s vast intangible cultural heritage resources, every intangible cultural heritage is a unique special existence, with its own particularity and difference, which contains huge cultural value. In the United
States, Japan and other relatively perfect countries have established a relatively sound brand consciousness, for example, Japanese animation, American Disney and Hollywood brand effect is huge, Disney from animation to the extension of all kinds of surrounding products, Japanese Miyazaki Hayao comics and its derivatives, bring rich economic value also spread the unique culture to the concept of consumers, pointed out the way for the development of the cultural industry. For the copper silver industry, building an original brand is the key to build the core competitiveness. Through the refining of the "usefulness", "scarcity" and "aggregation" elements, a resource combination with strong originality and core competitiveness is formed. [8] The intellectual property IP will be connected with the Black Copper Walking on Silver industry, and the well-known "Black Copper Walking on Silver" brand at home and abroad through games, animation, theme and other experience halls. Such as guangzhou song and dance theatre based on Guangzhou lion, many nanyue intangible heritage project as a creation element, with profound lingnan humanities as the carrier, the national dance and Guangdong lion dance, Guangdong lion unique skills into dance language, arranged the national dance "wake lion", made the Guangzhou lion dance intangible cultural heritage as the theme of IP, become an important name card of Guangzhou lion dance.

\subsection{Improve the Digital Development Model}

The combination of the inheritance and protection of digital technology and intangible cultural heritage is a new development idea. The current development of digital technology provides reliable technical support for the development of copper silver, and digitalization will surely push the inheritance of Black Copper Walking on Silver to a new development situation. The rapid development of digital media and smartphones has made a qualitative leap in the transmission speed and range of information. Digital, visualization, humanization, mass storage, efficient storage and query, fast retrieval, data analysis, convenience and other characteristics show a strong characteristics and advantages of the times. [9] The preservation form of Yunnan black copper silver walking process still remains in the form of books, images and video, which is not conducive to long-term preservation. At present, with digital maturity, this traditional preservation method can no longer meet the development needs of black copper and silver walking. Use digital technology for digital existing data processing and digital modeling from internal structure, external materials and surface decoration, so as to achieve all-round threedimensional recording. Based on the basis of digital preservation, a digital display platform will be established, and three-dimensional models, panoramic display and other forms will be established to show the culture and skill process of Black Copper Walking on Silver to the audience in a dynamic form. For example, the production skills of Black Copper Walking on Silver can be multi-directional panoramic display, from the perspective of technology, material, structure, color and other analysis, so that modern people are more convenient to receive the information of Black Copper Walking on Silver walking technology. On the basis of storage and display, Black Copper Walking on Silver will use online platforms such as "We Media" and e-commerce for marketing, and effectively promote it in the form of public welfare publicity and "We Media" communication. Using digital technology to realize the new trend of online and 
offline development, and indirectly expand the popularity of Black Copper Walking on Silver, thus attracting larger consumer groups.

\section{Conclusion}

The Black Copper Walking on Silver technology has been passed on with its unique artistic charm. It is the crystallization of the wisdom and hot feelings hard explored by the people of Yunnan. As an indispensable part of the national culture, it needs to be passed down from generation to generation, and it also needs to keep pace with the times and innovate. As an important resource in the cultural industry, it is necessary to fully excavate the rich cultural connotation of Black Copper Walking on Silver, carry out effective docking and transformation with the cultural industry, and carry out effective inheritance and development of the black copper silver technology. Reasonable development, give into account the economic value and cultural value of Black Copper Walking on Silver, and realize the living inheritance of Black Copper Walking on Silver and the win-win situation of cultural industry.

\section{References}

[1] Zhang Yan, Luo Jingyan "Research on the Living Inheritance and Industrialization Development Mode of Tianjin Intangible Cultural Heritage", 18th Packaging Engineering 18,2018.
[2] Wu Wei; Process of Spot Copper and Black Copper and Silver Walking in Yunnan, Journal of Yunnan University for Nationalities (Philosophy and Social Sciences Edition), 2008.

[3] Wu Shuangcheng, Chu Rongbang: "The Magic of Yunnan Black Copper Walking on Silver (Gold) Technology", "Electroplating and Painting", Issue 4,2015.

[4] Feng Xiaoqin: Thoughts on the Characteristics and Protection of Ethnic Minority Intangible Cultural Heritage in Gansu Province, Issue 3 of Gansu Senior Teachers ' Journal, 2012.

[5] Zheng Yanqi; Analysis of Traditional Handicraft — to Yunnan "Black Copper Walking on Silver " skills as an example, Research of National Art, 2013.

[6] Sun Tian: Research on the Industrialization Development Path of Intangible Cultural Heritage — Taking the Protection and Inheritance Practice of Intangible Cultural Heritage in Mountain Province as an example, Issue 1 of Art Hundred Schools, 2018.

[7] Tang Mango, Meng Tao; Research on Production Protection Mode and Pathath of Wushu Intangible Cultural Heritage, Journal of Nanjing Institute of Sport (Social Science Edition), 2016.

[8] Yu zhu; Industrialization Development Strategy of Jilin Intangible Cultural Heritage, Frontier Economy and Culture, Issue 12,2013.

[9] Qin Yang, Li Guanyu: On the Development Strategy of the Application and Inheritance of Regional Art " Intangible Cultural Heritage in the New Era, Issue 1 of Art Hundred Schools, 2018. 